\title{
Milk production and nutrient digestibility responses to triglyceride or fatty acid supplements enriched in palmitic acid
}

\author{
J. de Souza* and A. L. Lock† \\ Department of Animal Science, Michigan State University, East Lansing 48824
}

\begin{abstract}
The objective of our study was to evaluate the effects of feeding triglyceride and fatty acid (FA) supplements enriched in palmitic acid (PA; C16:0) on production and nutrient digestibility responses of mid-lactation dairy cows. Fifteen Holstein cows $(137 \pm 49 \mathrm{~d}$ in milk) were randomly assigned to a treatment sequence in a $3 \times 3$ Latin square design. Treatments consisted of a control diet (CON; no added PA) or $1.5 \% \mathrm{FA}$ added as either a FA supplement (PA-FA) or a triglyceride supplement (PA-TG). The PA supplements replaced soyhulls, and diets were balanced for glycerol content. Periods were $21 \mathrm{~d}$ in length with sample and data collection occurring during the final $5 \mathrm{~d}$. Compared with CON, PA treatments increased dry matter (66.5 vs. $63.9 \%$ ) and neutral detergent fiber (NDF) apparent digestibility (42.0 vs. $38.2 \%$ ). Although PA treatments tended to increase 18-carbon FA apparent digestibility (79.1 vs. $77.9 \%)$, PA treatments decreased 16-carbon (63.1 vs. $75.8 \%)$ and total FA (72.0 vs. $76.5 \%)$ apparent digestibilities compared with CON. The PA treatments increased milk fat content (3.60 vs. $3.41 \%)$, milk fat yield (1.70 vs. $1.60 \mathrm{~kg} / \mathrm{d})$, yield of 16-carbon milk FA $(570$ vs. $471 \mathrm{~g} / \mathrm{d}), 3.5 \%$ fat-corrected milk ( 47.6 vs. 46.5 $\mathrm{kg} / \mathrm{d}$ ), and energy-corrected milk (47.4 vs. $46.6 \mathrm{~kg} / \mathrm{d}$ ) compared with CON. The PA treatments did not affect dry matter intake (28.5 vs. $29.2 \mathrm{~kg} / \mathrm{d})$, milk yield ( 47.0 vs. $47.4 \mathrm{~kg} / \mathrm{d}$ ), milk protein yield (1.42 vs. $1.45 \mathrm{~kg} / \mathrm{d}$ ), milk lactose yield ( 2.29 vs. $2.31 \mathrm{~kg} / \mathrm{d}$ ), yield of $<16$-carbon milk FA (360 vs. $370 \mathrm{~g} / \mathrm{d}$ ), yield of $>16$-carbon milk FA (642 vs. $630 \mathrm{~g} / \mathrm{d}$ ), body weight (720 vs. 723 $\mathrm{kg}$ ), or body condition score (3.14 vs. 3.23 ). We did not observe differences in digestibilities of dry matter, NDF, and 18-carbon FA between PA-TG and PAFA. In contrast, PA-FA increased 16-carbon (68.6 vs. $57.6 \%$ ) and total FA apparent digestibility (73.8 vs. $70.1 \%$ ) compared with PA-TG. This resulted in PA-FA
\end{abstract}

Received September 14, 2018.

Accepted January 22, 2019.

*Current address: Perdue Agribusiness, Salisbury, MD 21804.

$\dagger$ Corresponding author: allock@msu.edu supplementation increasing the apparent digestibility of the PA supplement by $\sim 10$ percentage points compared with PA-TG. Compared with PA-TG, PA-FA increased 16-carbon FA intake by $60 \mathrm{~g} / \mathrm{d}$, absorbed 16-carbon FA by $86 \mathrm{~g} / \mathrm{d}$, and absorbed total FA by $85 \mathrm{~g} / \mathrm{d}$. Compared with PA-TG, PA-FA increased dry matter intake (29.1 vs. $27.8 \mathrm{~kg} / \mathrm{d}$ ), yield of 16-carbon milk FA (596 vs. 545 $\mathrm{g} / \mathrm{d}$ ), and tended to increase milk yield (47.6 vs. 46.4 $\mathrm{kg} / \mathrm{d})$, milk fat yield (1.70 vs. $1.66 \mathrm{~kg} / \mathrm{d})$, and $3.5 \%$ fat-corrected milk (48.1 vs. $47.2 \mathrm{~kg} / \mathrm{d}$ ). In conclusion, the production response of dairy cows to PA tended to be greater for a FA supplement compared with a triglyceride supplement. Overall, PA increased NDF digestibility, milk fat yield, energy-corrected milk, and feed efficiency in mid-lactation dairy cows.

Key words: digestibility, palmitic acid, triglyceride, dairy cow

\section{INTRODUCTION}

Fat supplements are added to dairy cow diets to increase dietary energy density, feed efficiency, yields of milk and milk fat, and to improve energy balance (Palmquist, 1994; Rabiee et al., 2012). Individual fatty acids (FA) can have different effects, and recently, considerable research has focused on palmitic acid (C16:0) supplementation. This FA has been reported to increase milk yield, milk fat concentration and yield, and the efficiency of milk production compared with a control diet (Mosley et al., 2007; Lock et al., 2013; de Souza et al., 2017) and with other FA supplements (Rico et al., 2014a,b; de Souza et al., 2018). However, variation in response to $\mathrm{C} 16: 0$ has also been reported, with some studies reporting no effect of C16:0 supplementation on milk yield (Lock et al., 2013; Rico et al., 2014a), whereas others reported increases in milk yield (Mosley et al., 2007; Piantoni et al., 2013; de Souza and Lock, 2018a). Because the supplements described in the above-mentioned studies were similar in FA composition, understanding factors (e.g., basal diet composition, characteristics of fat supplements) that are associated with variations in production responses may allow for more precise feeding recommendations. 
The degree of esterification of fat supplements has been suggested as a factor that may affect FA digestibility, and consequently, production responses of dairy cows (Elliott et al., 1994; Pantoja et al., 1995). Under normal conditions most FA reaching the intestine are free FA (Doreau and Chilliard, 1997); therefore, these previous studies suggested that lipolysis in the small intestine maybe a rate-limiting step in digestion of triglyceride (TG) sources of fat. Recently, we observed that feeding a C16:0 TG supplement $(77 \% \mathrm{C} 16: 0$ and $5 \%$ C18:0) reduced total FA digestibility by $8.7 \%$ units compared with a Ca-salts of palm FA (de Souza and Lock, 2018b). Similar to our results, Weiss et al. (2011) observed that total FA digestibility was reduced $\sim 8$ percentage points when a saturated TG supplement containing $72 \% \mathrm{C} 16: 0$ and 5\% C18:0 was fed, compared with a control diet. However, the decrease in FA digestibility observed by Weiss et al. (2011) and de Souza and Lock (2018b) is smaller than that previously reported in studies that fed saturated TG supplements, in which total FA digestibility ranged from 33 to $62 \%$ (e.g., Pantoja et al., 1995; Elliott et al., 1999; Weiss and Wyatt, 2004). A possible factor affecting variation in FA digestibility due to feeding TG fat supplements in previous studies is differences in the FA profile of the supplements examined. To our knowledge, most published studies evaluating the effect of C16:0 supplementation on dairy cow responses were conducted utilizing FA rather than TG supplements. Because the FA profile of fat supplements seems to be an important factor affecting FA digestibility, evaluating the effect of the degree of esterification in supplements with similar FA profiles is of importance.

The objective of our study was to evaluate the effects of commercially available C16:0 supplements fed either as FA or TG supplements on nutrient digestibility and production responses of mid-lactation dairy cows. We hypothesized that a C16:0 supplement fed as FA would have higher digestibility than the TG supplement, but that the differences would be smaller than previously reported in the literature due to differences in the FA profile of the supplements.

\section{MATERIALS AND METHODS}

\section{Design and Treatments}

All experimental procedures were approved by the Institutional Animal Care and Use Committee at Michigan State University, East Lansing. Fifteen midlactation Holstein cows at the Michigan State University Dairy Field Laboratory were randomly assigned to treatment sequence in replicated $3 \times 3$ Latin squares with 21-d periods. All animals received a common diet containing no supplemental fat during a 14-d preliminary period to obtain baseline values for response variables. At the beginning of the trial, mean DIM, BW, and ECM (mean $\pm \mathrm{SD}$ ) were $137 \pm 49 \mathrm{~d}, 700 \pm 52 \mathrm{~kg}$, and $48.1 \pm 6.1 \mathrm{~kg} / \mathrm{d}$, respectively.

Treatments were a control diet $(\mathbf{C O N}$; no added $\mathrm{PA}$ ) or $1.5 \%$ of FA added either as a FA supplement (PA-FA) or a triglyceride supplement (PA-TG). Chemical composition and characteristics of the PA supplements are presented in Table 1. The PA supplements replaced soyhulls in the diets, which were formulated to meet the requirements of the average cow in the group (NRC, 2001; Table 2). Both fat-supplemented diets were balanced for glycerol concentration; glycerol was not added to our CON treatment. Although it is important to consider a possible different metabolic fate for the glycerol fed in the diet or released from TG in the intestine (or both), it is unlikely that it affected our results due to the very small amount required to balance dietary glycerol content between the PA-TG and PA-FA diets. The DM concentration was determined twice weekly for forages and diets were adjusted when necessary. A basal diet mix (containing forage sources, corn grain, high-moisture corn, soybean meal, and mineral mix) was mixed daily in a mixer wagon. Then, the soyhulls, the fat supplements, and the basal diet were mixed in a tumble mixer for each experimental diet. Cows were housed in tiestalls throughout the experiment and milked twice daily (0400 and $1500 \mathrm{~h}$ ). Access to feed was blocked from 0800 to $1000 \mathrm{~h}$ for collection of orts and offering of new feed. Cows were fed $115 \%$ of expected intake at $1000 \mathrm{~h}$ daily. Water was available ad libitum in each stall and stalls were bedded with sawdust and cleaned twice daily.

Table 1. Physical characterization and composition of triglyceride (PA-TG) and fatty acid (PA-FA) palmitic acid supplements fed in treatment diets $(\mathrm{n}=3)^{1}$

\begin{tabular}{lcc}
\hline Item & PA-TG & PA-FA \\
\hline Mean particle size, $\mu \mathrm{m}$ & 746 & 750 \\
Melting point, ${ }^{\circ} \mathrm{C}$ & 59.0 & 57.7 \\
Iodine value & 16.8 & 12.3 \\
Glycerol, \% & 9.30 & 0.10 \\
Gross energy, Mcal/kg & 9.00 & 9.29 \\
Fatty acid (FA) profile, & & \\
g/100 g of FA & 1.10 & \\
14:0 & 78.6 & 8.17 \\
16:0 & 5.05 & 0.69 \\
18:0 & 13.5 & 8.75 \\
cis-9 18:1 $22: 0$ & 0.34 & 0.02 \\
\hline
\end{tabular}

${ }^{1}$ Average from composited samples taken during each period $(n=3)$. 


\section{Data and Sample Collection}

Samples and data for production results were collected during the last $5 \mathrm{~d}$ of each treatment period (d 17 to 21). Samples of all diet ingredients $(0.5 \mathrm{~kg})$ and orts from each cow $(12.5 \%)$ were collected daily and composited by period for analysis. Milk yield was recorded, and 2 milk samples were collected at each milking. One aliquot was collected in a sealed tube with preservative (bronopol tablet, D\&F Control Systems, San Ramon, $\mathrm{CA}$ ) and stored at $4^{\circ} \mathrm{C}$ for milk component analysis. The second aliquot was stored without preservative at $-20^{\circ} \mathrm{C}$ until analyzed for FA composition.

For apparent digestibility measurements, fecal samples $(\sim 400 \mathrm{~g})$ were collected every $15 \mathrm{~h}$ during the last $5 \mathrm{~d}$ of each period resulting in 8 samples per cow per period, representing every $3 \mathrm{~h}$ of a 24 -h period to account for diurnal variation. Feces were stored at $-20^{\circ} \mathrm{C}$ until samples were dried and composited on equal DM

Table 2. Ingredient and nutrient composition of treatment diets

\begin{tabular}{|c|c|c|c|}
\hline \multirow[b]{2}{*}{ Item } & \multicolumn{3}{|c|}{ Treatment $^{1}$} \\
\hline & $\mathrm{CON}$ & PA-TG & PA-FA \\
\hline \multicolumn{4}{|l|}{ Ingredient, $\%$ of DM } \\
\hline Corn silage & 22.1 & 22.1 & 22.1 \\
\hline Alfalfa silage & 15.3 & 15.3 & 15.3 \\
\hline Wheat straw & 4.60 & 4.60 & 4.60 \\
\hline Fine ground corn & 12.0 & 12.0 & 12.0 \\
\hline High-moisture corn & 12.0 & 12.0 & 12.0 \\
\hline Soybean meal $(48 \% \mathrm{CP})$ & 14.3 & 14.3 & 14.3 \\
\hline Soyhulls & 9.4 & 7.7 & 7.7 \\
\hline Whole cottonseed & 7.0 & 7.0 & 7.0 \\
\hline Palmitic acid triglyceride supplement ${ }^{2}$ & - & 1.69 & - \\
\hline Palmitic acid free fatty acid supplement ${ }^{3}$ & - & - & 1.54 \\
\hline Glycerin & - & - & 0.15 \\
\hline Mineral and vitamin $\operatorname{mix}^{4}$ & 2.0 & 2.0 & 2.0 \\
\hline Limestone & 0.60 & 0.60 & 0.60 \\
\hline Sodium bicarbonate & 0.71 & 0.71 & 0.71 \\
\hline \multicolumn{4}{|l|}{ Nutrient composition, \% of DM } \\
\hline $\mathrm{NDF}$ & 31.0 & 29.9 & 29.9 \\
\hline $\mathrm{CP}$ & 16.7 & 16.6 & 16.6 \\
\hline Starch & 26.0 & 25.9 & 26.0 \\
\hline Total fatty acids & 3.37 & 4.83 & 4.83 \\
\hline $16: 0$ & 0.55 & 1.70 & 1.85 \\
\hline $18: 0$ & 0.08 & 0.16 & 0.11 \\
\hline cis-9 18:1 & 0.59 & 0.79 & 0.71 \\
\hline cis-9, cis-12 18:2 & 1.72 & 1.75 & 1.74 \\
\hline cis-9,cis-12,cis-15 18:3 & 0.19 & 0.19 & 0.19 \\
\hline
\end{tabular}

${ }^{1} \mathrm{CON}=$ control diet, no addition of palmitic acid; PA-TG = palmitic acid fed as triglyceride; PA-FA = palmitic acid fed as free fatty acid.

${ }^{2}$ Palmitic acid triglyceride supplement (BergaFat T300, Berg + Schmidt GmbH \& Co. KG, Hamburg, Germany).

${ }^{3}$ Palmitic acid free fatty acid supplement (BergaFat F100, Berg + Schmidt GmbH \& Co. KG).

${ }^{4}$ Vitamin and mineral mix contained $34.1 \%$ dry ground shelled corn, $25.6 \%$ white salt, $21.8 \%$ calcium carbonate, $9.1 \%$ Biofos (The Mosaic Co., Plymouth, MN), 3.9\% magnesium oxide, $2 \%$ soybean oil, and $<1 \%$ of each of the following: manganese sulfate, zinc sulfate, ferrous sulfate, copper sulfate, iodine, cobalt carbonate, vitamin E, vitamin A, vitamin $\mathrm{D}$, and selenium. basis for each cow period. Body weight was measured 3 times per week and 4 trained investigators determined $\mathrm{BCS}$ on a 5 -point scale in 0.25 increments on the last day of each period (Wildman et al., 1982).

\section{Sample Analysis}

Diet ingredients, orts, and fecal samples were dried at $55^{\circ} \mathrm{C}$ in a forced-air oven for $72 \mathrm{~h}$ for $\mathrm{DM}$ determination. Dried samples were ground with a Wiley mill (1 mm screen, Arthur H. Thomas, Philadelphia, PA). Samples of feed ingredients, orts, and feces were analyzed for ash, NDF, indigestible NDF, CP, starch, and FA concentration as described by Boerman et al. (2017). Indigestible NDF was used as an internal marker to estimate fecal output to determine apparent total-tract digestibility of nutrients (Cochran et al., 1986). Indigestible NDF was estimated as NDF after a 240-h in vitro fermentation (Van Soest et al., 1991). Particle size of the fat supplement was determined (method 965.22; AOAC, 1990) as described by de Souza et al. (2017). Fat supplements were analyzed for melting point (AOCS, 2013, method Cc 1-25), iodine value (AOCS, 2013, method Cd 1d-92), concentration of glycerol (AOCS, 2013, method Ca 14-56), and gross energy with bomb calorimetry by Eurofins Global Inc. (Des Moines, IA). Digestibility of supplemental fat was estimated with a Lucas test. The intake of FA from the basal diet was subtracted from that in each supplemented diet to calculate supplemental FA intake. Fecal output of undigested basal FA was estimated using FA digestibility measured when cows were fed the control diet and that value was used for each specific cow. We did not observe a period effect for total FA digestibility $(P=0.30)$, so we applied the FA digestibility when cows received the control diets to when they received treatment diets during other periods. Fecal output of basal FA was subtracted from fecal output of total FA when cows were fed the supplemented diets. Digestibility of supplemental fat was estimated with a Lucas test by regressing supplemental FA intake by supplemental FA absorbed. The slope of each regression is the estimated apparent digestibility coefficient of each fat supplement.

Individual milk samples were analyzed for fat, true protein, and lactose concentrations by mid-infrared spectroscopy (AOAC, 1990, method 972.160) by the Michigan Herd Improvement Association (Universal Lab Services, Lansing, MI). Yields of $3.5 \%$ FCM, ECM, and milk components were calculated using milk yield and component concentrations for each milking, summed for a daily total, and averaged for each collection period. Milk samples used for analysis of FA composition were composited based on milk fat yield (d 
17-21 of each period). Milk lipids were extracted, and FAME prepared according to our methods previously described by Lock et al. (2013). Yield of individual FA in milk fat were calculated by correcting for glycerol content and other milk lipid classes according to Piantoni et al. (2013).

The FA yield response to additional FA intake (FAYR-INT) was calculated as

\section{FAYR-INT $(\%)=[(\mathrm{FA}$ yield for PA}

supplemented diet - FA yield for $\mathrm{CON}) /(\mathrm{FA}$ intake for

PA supplemented diet - FA intake for CON)] $\times 100$.

The FA yield response to additional absorbed FA (FAYR-ABS) was calculated as

FAYR-ABS $(\%)=[(\mathrm{FA}$ yield for PA supplemented

diet - FA yield for CON)/(absorbed FA for PA

supplemented diet - absorbed FA for CON)] $\times 100$.

\section{Statistical Analysis}

All data were analyzed using the mixed model procedure of SAS (version 9.4, SAS Institute, Cary, NC). Data were analyzed using the following model:

$$
\mathrm{Y}_{\mathrm{ijkl}}=\mu+\mathrm{C}(\mathrm{S})_{\mathrm{i}(\mathrm{j})}+\mathrm{S}_{\mathrm{j}}+\mathrm{P}_{\mathrm{k}}+\mathrm{T}_{\mathrm{l}}+\mathrm{e}_{\mathrm{ijkl}} \text {, }
$$

where $Y_{i j k l}=$ the dependent variable, $\mu=$ the overall mean, $\mathrm{C}(\mathrm{S})_{\mathrm{i}(\mathrm{j})}=$ random effect of cow nested in sequence $(\mathrm{i}=1$ to 15$), \mathrm{S}_{\mathrm{j}}=$ random effect of treatment sequence $(\mathrm{j}=1$ to 6$), \mathrm{P}_{\mathrm{k}}=$ fixed effect of period $(\mathrm{k}=1$ to 3$), \mathrm{T}_{1}=$ fixed effect of treatment $(\mathrm{l}=1$ to 3$)$, and $\mathrm{e}_{\mathrm{ijkl}}$ $=$ residual error. The interaction between period and treatment was initially included in the model but was removed because it was not significant (all $P>0.20$ ). Two preplanned contrasts were used to evaluate (1) the overall effect of PA supplemented treatments [CON vs. PA; 1/2 (PA-TG + PA-FA)], and (2) the effect of $\mathrm{PA}$ supplement (PA-TG vs. PA-FA). Contrasts were declared significant at $P \leq 0.05$ and trends at $0.05<$ $P \leq 0.10$.

\section{RESULTS}

Compared with CON, PA treatments did not affect DMI $(P=0.13)$ but increased DM digestibility $(P<$ $0.01)$ and NDF digestibility $(P<0.01$, Table 3$)$. The PA treatments increased 16-carbon and total FA intake (both $P<0.01$ ) and tended to increase 18-carbon FA intake $(P=0.06)$ compared with CON. The PA treatments decreased 16-carbon and total FA appar- ent digestibilities (both $P<0.01$ ) but tended to increase 18-carbon FA apparent digestibility $(P=0.10)$. Also, compared with CON, PA treatments increased absorbed 16-carbon, 18-carbon, and total FA (all $P<$ 0.05). Compared with PA-TG, PA-FA increased DMI $(P=0.05)$, but we did not observe differences in digestibilities of DM, NDF, or 18-carbon FA between PA-TG and PA-FA (all $P>0.50)$. In contrast, PA-FA increased 16-carbon $(P<0.01)$ and total FA apparent digestibility $(P=0.02)$ compared with PA-TG. Compared with PA-TG, PA-FA increased 16-carbon FA intake by $60 \mathrm{~g} / \mathrm{d}(P<0.01)$ and increased absorbed 16-carbon FA by $86 \mathrm{~g} / \mathrm{d}(P<0.01)$ and absorbed total FA by 85 $\mathrm{g} / \mathrm{d}(P<0.01)$. We estimated that the apparent digestibility of the basal diet (without supplemental fat) was $76.2 \%$ (Figure 1A). Additionally, by using a Lucas test we estimated that PA-FA increased apparent digestibility of supplemental fat by $\sim 10$ percentage points compared with PA-TG (69.5 vs. $59.0 \%$ for PA-FA and PA-TG, respectively; Figure 1B).

Compared with CON, PA treatments did not affect milk yield $(P=0.67$; Table 4$)$. In contrast, PA treatments increased milk fat content $(P<0.01)$, milk fat yield $(P<0.01), 3.5 \%$ FCM $(P=0.01)$, and ECM $(P=0.04)$ compared with CON. Additionally, the PA treatments increased feed efficiency (ECM/DMI; $P<$ $0.01)$, but reduced BW change $(P=0.01)$ compared with CON. Compared with PA-TG, PA-FA tended to increase milk yield $(P=0.06)$, milk fat yield $(P=$ $0.10)$, and $3.5 \% \mathrm{FCM}(P=0.09)$. We did not observe differences in concentrations or yields of milk protein and lactose, or in feed efficiency, between PA-TG and PA-FA (all $P<0.10$ ). The PA-FA increased BW change $(P=0.05)$ and BCS $(P=0.03)$ compared with PA-TG.

Milk FA are derived from 2 sources: $<16$ carbon FA from de novo synthesis in the mammary gland and $>16$ carbon FA originating from extraction from plasma. Mixed-source FA (16-carbon) originate from de novo synthesis in the mammary gland and extraction from plasma. Compared with CON, PA treatments reduced the concentration of $<16$-carbon and $>16$-carbon (all $P$ $<0.01$; Table 5) but increased 16-carbon milk FA $(P<$ $0.01)$. On a yield basis, PA treatments increased 16-carbon milk FA $(P<0.01)$ due primarily to the increase in concentration and yield of $\mathrm{C} 16: 0(P<0.01$; Table $6)$. In contrast, PA treatments did not affect the yield of $<16$-carbon milk FA $(P=0.23)$ or $>16$-carbon milk FA $(P=0.56)$. Additionally, PA treatments increased yield of cis-9 C18:1 $(P<0.01)$. Compared with PA-TG, PA-FA increased the concentration and yield of 16-carbon FA (both $P<0.01$ ) primarily due to the greater increase in concentration and yield of C16:0 $(P<0.01)$. In contrast, PA-FA decreased the concentration $(P<$ $0.01)$ and yield $(P=0.03)$ of $>16$-carbon milk FA due 
Table 3. Nutrient intake and apparent digestibility and absorbed 16-carbon, 18-carbon, and total fatty acids (FA) for cows fed treatment diets $(\mathrm{n}=15)$

\begin{tabular}{|c|c|c|c|c|c|c|}
\hline \multirow[b]{2}{*}{ Variable } & \multicolumn{3}{|c|}{ Treatment $^{1}$} & \multirow[b]{2}{*}{ SEM } & \multicolumn{2}{|c|}{ Contrast $^{2}$} \\
\hline & $\mathrm{CON}$ & PA-TG & PA-FA & & CON vs. PA & PA-TG vs. PA-FA \\
\hline \multicolumn{7}{|l|}{ Intake, $\mathrm{kg} / \mathrm{d}$} \\
\hline $\mathrm{DM}$ & 29.2 & 27.8 & 29.1 & 0.77 & 0.13 & 0.05 \\
\hline $\mathrm{NDF}$ & 9.01 & 8.29 & 8.69 & 0.27 & 0.01 & 0.08 \\
\hline \multicolumn{7}{|l|}{ Intake, $\mathrm{g} / \mathrm{d}$} \\
\hline Total FA & 990 & 1,370 & 1,410 & 37.2 & $<0.01$ & 0.13 \\
\hline 16-Carbon & 180 & 500 & 560 & 14.2 & $<0.01$ & $<0.01$ \\
\hline 18-Carbon & 770 & 820 & 810 & 23.8 & 0.06 & 0.45 \\
\hline \multicolumn{7}{|l|}{ Digestibility, \% } \\
\hline $\mathrm{DM}$ & 63.9 & 66.5 & 66.4 & 0.37 & $<0.01$ & 0.71 \\
\hline $\mathrm{NDF}$ & 38.2 & 42.1 & 41.8 & 0.38 & $<0.01$ & 0.59 \\
\hline Total FA & 76.5 & 70.1 & 73.8 & 1.10 & $<0.01$ & 0.02 \\
\hline 16-Carbon & 75.8 & 57.6 & 68.6 & 1.83 & $<0.01$ & $<0.01$ \\
\hline 18-Carbon & 77.9 & 78.6 & 79.6 & 1.08 & 0.10 & 0.52 \\
\hline \multicolumn{7}{|l|}{ Absorbed, g/d } \\
\hline Total FA & 763 & 957 & 1,041 & 29.3 & $<0.01$ & $<0.01$ \\
\hline 16-Carbon & 141 & 288 & 374 & 11.8 & $<0.01$ & $<0.01$ \\
\hline 18-Carbon & 605 & 646 & 640 & 19.7 & 0.05 & 0.77 \\
\hline
\end{tabular}

${ }^{1} \mathrm{CON}=$ control diet, no addition of palmitic acid; PA-TG = palmitic acid fed as triglyceride supplement; PA$\mathrm{FA}=$ palmitic acid fed as free fatty acid supplement.

${ }^{2} P$-values associated with contrasts: (1) the effect of PA treatments [CON vs. PA; 1/2(PA-TG + PA-FA)], and

(2) the effect of palmitic acid fed as triglycerides or free fatty acids (PA-TG vs. PA-FA).

to a lower yield of cis-9 C18:1 $(P=0.01)$ compared with PA-TG. The FAYR-INT was 18.4 and $23.8 \%$ for PA-TG and PA-FA, respectively. The FAYR-ABS was 36.0 and $36.1 \%$ for PA-TG and PA-FA, respectively.

\section{DISCUSSION}

Changes in intake and nutrient digestibility due to supplemental fat may affect, positively or negatively, digestible energy available for milk production, body reserves, or both (Boerman et al., 2015). In this regard, understanding factors that influence FA digestibility are useful in developing strategies for diet formulation and provide information critical for optimal FA supplementation. The digestibility of fat supplements fed as TG has been shown to be lower than the digestibility of fat supplements fed as FA (Elliott et al., 1999; Pantoja et al., 1995; Weiss and Wyatt, 2004). However, the TG supplements in most previous studies contained higher proportions of $\mathrm{C} 18: 0$ as the major FA. Therefore, these results might not only be influenced by the degree of esterification, but also by the FA profile of the supplement fed. Although considerable research has recently examined the effect of C16:0 supplements, to our knowledge, most published studies with dairy cows used FA rather than TG supplements. Due to the importance of FA digestibility when evaluating fat supplements, we conducted the current experiment to examine the effects of degree of esterification of C16:0 supplements on production responses of dairy cows.
The use of enriched C16:0 supplements with similar FA profile in the present experiment allowed us to compare the effects of degree of esterification while minimizing potential confounding effects of large differences in other FA in the supplements.

Overall, PA treatments did not affect DMI, which agrees with results from studies feeding enriched $(\geq 85 \%)$ sources of $\mathrm{C} 16: 0$ in which DMI has not been reduced compared with a control diet (Piantoni et al., 2013; de Souza et al., 2017). In addition, in a metaregression of 29 treatment means compiled from the literature, Allen (2000) observed that saturated hydrogenated FA supplements did not affect DMI. In our current study, PA-TG decreased DMI compared with PA-FA, whereas we recently observed lower DMI for a Ca-salts of palm FA supplement compared with a PA-TG supplement (de Souza and Lock, 2018b). Contrary to our results, Litherland et al. (2005) observed that abomasal infusion of soy oil as FA decreased DMI compared with an equivalent amount of soy oil as TG. In this regard, Bremmer et al. (1998) suggested that esterification of FA to glycerol may alter the sensing mechanism in the upper duodenum by which FA inhibit DMI. Reasons for the differences between our results and the above-mentioned studies may include differences in the FA profiles of the supplements and, possibly, the production level of the cows studied. Further research is needed to evaluate these inconsistent results and to elucidate the mechanisms regulating feed intake when FA and TG supplements are fed. 
A

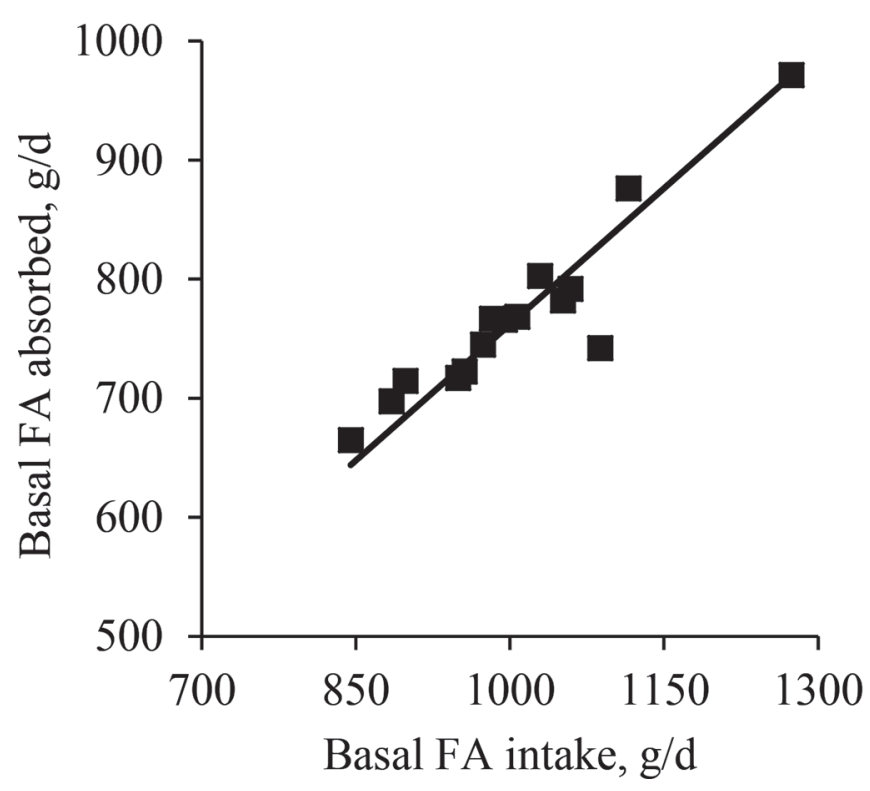

$\mathrm{B}$

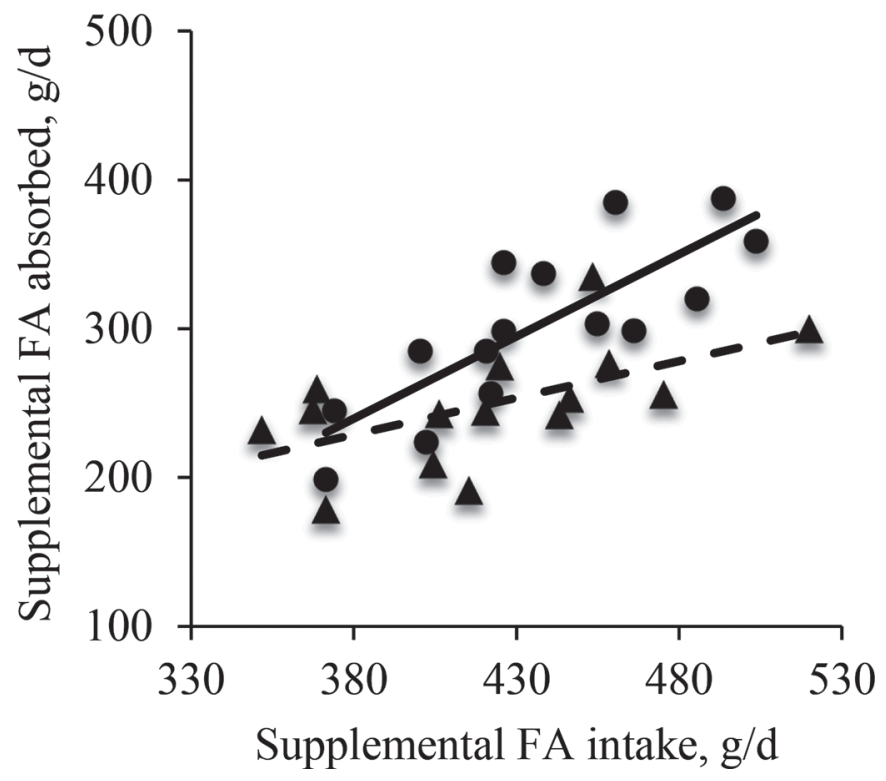

Figure 1. Lucas test to estimate the apparent fatty acid (FA) digestibility of the basal diet (A) and palmitic acid-enriched supplements (B) fed as triglycerides (PA-TG, triangles and dashed line) or fatty acids (PA-FA, circles and solid line). To estimate the FA digestibility of the basal diet, a Lucas test was used regressing basal FA intake by basal FA absorbed for each cow when they received the control diet. To estimate the digestibility of the supplements, the intake of FA from the basal diet was subtracted from that in each supplemented diet to calculate the supplemental FA intake. Fecal output of undigested basal FA was estimated using FA digestibility measured when cows were fed the control diet and that value was used for individual cows. Fecal output of basal FA was subtracted from fecal output of total FA when cows were fed the supplemented diets. The slopes (i.e., apparent digestibility of supplemental fat) were $0.762 \pm 0.089,0.590 \pm 0.019$, and $0.695 \pm 0.021$ for control, PA-TG, and PA-FA, respectively, and intercepts were not different from zero $(P>0.59)$.

Table 4. Milk yield, milk composition, BW, and BCS for cows fed treatment diets $(\mathrm{n}=15)$

\begin{tabular}{|c|c|c|c|c|c|c|}
\hline \multirow[b]{2}{*}{ Variable } & \multicolumn{3}{|c|}{ Treatment $^{1}$} & \multirow[b]{2}{*}{ SEM } & \multicolumn{2}{|c|}{ Contrast $^{2}$} \\
\hline & $\mathrm{CON}$ & PA-TG & PA-FA & & CON vs. PA & PA-TG vs. PA-FA \\
\hline \multicolumn{7}{|l|}{ Milk yield, $\mathrm{kg} / \mathrm{d}$} \\
\hline Milk & 47.4 & 46.4 & 47.6 & 1.13 & 0.67 & 0.06 \\
\hline $3.5 \% \mathrm{FCM}^{3}$ & 46.6 & 47.2 & 48.0 & 1.09 & 0.01 & 0.09 \\
\hline $\mathrm{ECM}^{4}$ & 46.7 & 47.0 & 47.6 & 0.94 & 0.04 & 0.14 \\
\hline \multicolumn{7}{|l|}{ Milk composition } \\
\hline Fat, $\mathrm{kg} / \mathrm{d}$ & 1.60 & 1.66 & 1.70 & 0.02 & $<0.01$ & 0.10 \\
\hline Fat, $\%$ & 3.41 & 3.61 & 3.59 & 0.09 & $<0.01$ & 0.47 \\
\hline Protein, $\mathrm{kg} / \mathrm{d}$ & 1.45 & 1.40 & 1.43 & 0.03 & 0.15 & 0.52 \\
\hline Protein, $\%$ & 3.10 & 3.04 & 3.04 & 0.02 & $<0.01$ & 0.39 \\
\hline Lactose, $\mathrm{kg} / \mathrm{d}$ & 2.31 & 2.27 & 2.30 & 0.06 & 0.46 & 0.76 \\
\hline Lactose, \% & 4.89 & 4.88 & 4.86 & 0.03 & 0.39 & 0.22 \\
\hline ECM/DMI & 1.59 & 1.69 & 1.64 & 0.03 & $<0.01$ & 0.78 \\
\hline $\mathrm{BW}, \mathrm{kg}$ & 723 & 719 & 725 & 17.9 & 0.80 & 0.15 \\
\hline BW change, $\mathrm{kg} / \mathrm{d}$ & 0.65 & 0.25 & 0.50 & 0.19 & 0.01 & 0.05 \\
\hline BCS & 3.14 & 3.15 & 3.23 & 0.03 & 0.17 & 0.03 \\
\hline BCS change & 0.07 & 0.008 & 0.06 & 0.03 & 0.12 & 0.15 \\
\hline
\end{tabular}

${ }^{1} \mathrm{CON}=$ control diet, no addition of palmitic acid; PA-TG = palmitic acid fed as triglyceride supplement; PA$\mathrm{FA}=$ palmitic acid fed as free fatty acid supplement.

${ }^{2} P$-values associated with contrasts: (1) the effect of PA treatments [CON vs. PA; $\left.1 / 2(\mathrm{PA}-\mathrm{TG}+\mathrm{PA}-\mathrm{FA})\right]$, and

(2) the effect of palmitic acid fed as triglycerides or free fatty acid (PA-TG vs. PA-FA).

${ }^{3} 3.5 \% \mathrm{FCM}=[(0.4324 \times \mathrm{kg}$ of milk $)+(16.216 \times \mathrm{kg}$ of milk fat $)]$.

${ }^{4} \mathrm{ECM}=[(0.327 \times \mathrm{kg}$ of milk $)+(12.95 \times \mathrm{kg}$ of milk fat $)+(7.20 \times \mathrm{kg}$ of milk protein $)$. 
Table 5. Milk fatty acid (FA) profile for cows fed treatment diets $(\mathrm{n}=15)$

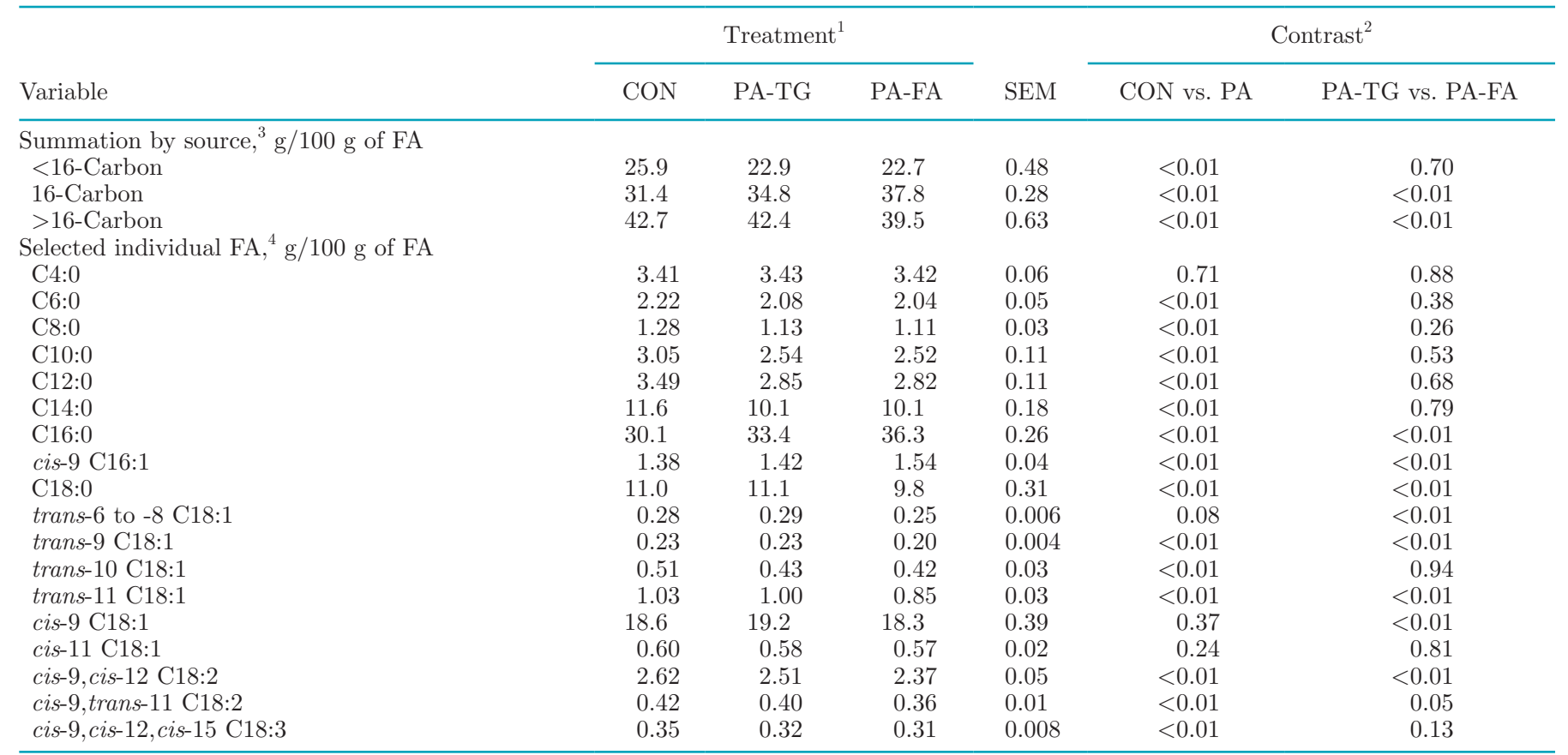

${ }^{1} \mathrm{CON}=$ control diet, no addition of palmitic acid; PA-TG $=$ palmitic acid fed as triglyceride supplement; PA-FA $=$ palmitic acid fed as free fatty acid supplement.

${ }^{2} P$-values associated with contrasts: $(1)$ the effect of PA treatments [CON vs. PA; $\left.1 / 2(\mathrm{PA}-\mathrm{TG}+\mathrm{PA}-\mathrm{FA})\right]$, and (2) the effect of palmitic acid fed as triglycerides or free FA (PA-TG vs. PA-FA).

${ }^{3}$ De novo FA originate from mammary de novo synthesis ( $<16$ carbons), preformed FA originate from extraction from plasma ( $>16$ carbons), and 16-carbon FA originate from both sources (C16:0 plus cis-9 C16:1).

${ }^{4} \mathrm{~A}$ total of approximately 80 individual FA were quantified. Only select FA are reported in the table.

When fed at typical inclusion rates ( $\leq 3 \%$ of $\operatorname{diet} \mathrm{DM})$, fat supplements minimally influence the digestibility of large aggregated fractions, such as DM digestibility, even when the digestibility of total FA differs markedly (Grummer, 1988; Weiss and Wyatt, 2004). However, if the supplement has effects on fiber digestion, DM digestibility can be affected (Simas et al., 1998). In our study, PA treatments increased both NDF and DM digestibility compared with CON. This increased NDF digestibility agrees with previous studies feeding C16:0 as a FA supplement (Piantoni et al., 2013; de Souza et al., 2017, 2018) and TG supplement (de Souza and Lock, 2018b). Although the mechanisms for this effect on fiber digestion due to feeding C16:0 are unknown, possible factors include an increase in retention time driven by an increase in cholecystokinin secretion (Piantoni et al., 2013), improvements in growth of Butyrivibrio bacteria in the rumen (Hackmann and Firkins, 2015), or both. de Souza et al. (2018) suggested that the FA profile of supplemental fat may affect NDF digestibility because we observed that feeding a FA blend with high content of $\mathrm{C} 16: 0(80 \% \mathrm{C} 16: 0)$ and a FA blend with $45 \%$ C16:0 and 35\% cis-9 C18:1 increased NDF digestibility compared with a nonfat control diet and a diet supplemented with a FA blend with $40 \%$ C16:0 and 40\% C18:0.

We observed that compared with CON, PA treatments reduced the digestibility of 16-carbon FA and total FA. Although Rico et al. (2014a) reported that feeding a highly enriched C16:0 supplement had positive effects on 16-carbon and total FA digestibilities of low-producing cows, other studies with high-producing cows have observed reductions in FA digestibility when feeding similar supplements (de Souza et al., 2017; de Souza and Lock, 2018a). In a recent meta-analysis, Boerman et al. (2015) observed no reduction in FA digestibility when the duodenal flow of C16:0 increased up to $500 \mathrm{~g} / \mathrm{d}$, whereas increasing the duodenal flow of C18:0 to the same level reduced FA digestibility. Although total flow of FA at the duodenum affects FA digestibility (Boerman et al., 2015), the profile of FA entering the duodenum is a critical factor affecting FA digestibility (Doreau and Chilliard, 1997; Rico et al., 2017; de Souza et al., 2018). In our study, although the intake of 16-carbon FA was slightly over $500 \mathrm{~g} / \mathrm{d}$ for the PA treatments and we observed that PA treatments reduced FA digestibility, this reduction was similar to that observed by de Souza et al. (2017) and lower than 
that reported by Piantoni et al. (2013). Although the exact mechanisms for the reduction in FA digestibility as FA intake increases are unknown, potential causes have been suggested and include competition for absorption sites and limits in emulsification (Drackley, 2000).

Previous studies have reported lower FA digestibility for fat supplements fed as TG compared with those fed as FA (Elliott et al., 1999; Weiss and Wyatt, 2004). Pantoja et al. (1995) observed reduced intestinal digestibility of 16-carbon, 18-carbon, and total FA when a partially hydrogenated tallow TG supplement was fed, compared with a partially hydrogenated tallow FA supplement. Therefore, lipolysis in the small intestine might be a rate-limiting step to TG supplement digestion; because several lipases are only active at the distal end of the small intestine, they may be unable to hydrolyze large amounts of duodenal TG when these supplements are fed, therefore possibly limiting intestinal digestibility (Jenkins and Jenny, 1992). In our study, we observed that PA-TG reduced total FA digestibility compared with PA-FA. However, the decrease in FA digestibility was smaller than that previously reported by the above-mentioned studies. We propose that this inconsistency is due to differences in the FA profile of the supplements being evaluated. Johnson et al. (1974) reported lower intestinal hydrolysis in sheep for tallow compared with coconut oil, olive oil, and corn oil. This was attributed to lower lipase activity resulting from lower solubility and poor emulsification of tallow due to its FA profile. Therefore, the lower solubility of TG enriched with C18:0 may increase the need for emulsification compounds to form micelles and reduce the time of action for intestinal lipases and FA absorption. Additionally, in our meta-analysis evaluating the digestibility of individual FA using duodenally cannulated cows, we determined that as the amount of C18:0 reaching the duodenum increased, the digestibility of C18:0 linearly decreased across nonsupplemented and fat-supplemented diets encompassing a wide range of C18:0 duodenal flows (Boerman et al., 2015). Also, the estimated digestibility of the PA-TG supplement in our study estimated by the Lucas test (59\%) was similar to the values estimated by Weiss et al. (2011) and de Souza and Lock (2018b) for their TG supplements. Although we did not measure it in our study, it is possible that our PA-TG supplement could have been partially hydrolyzed in the rumen, resulting in less intact TG

Table 6. Milk fatty acid yields for cows fed treatment diets $(\mathrm{n}=15)$

\begin{tabular}{|c|c|c|c|c|c|c|}
\hline \multirow[b]{2}{*}{ Variable } & \multicolumn{3}{|c|}{ Treatment $^{1}$} & \multirow[b]{2}{*}{ SEM } & \multicolumn{2}{|c|}{ Contrast $^{2}$} \\
\hline & $\mathrm{CON}$ & PA-TG & PA-FA & & CON vs. PA & PA-TG vs. PA-FA \\
\hline \multicolumn{7}{|l|}{ Summation by source, ${ }^{3} \mathrm{~g} / \mathrm{d}$} \\
\hline$<16$-Carbon & 370 & 359 & 361 & 21.3 & 0.23 & 0.93 \\
\hline 16-Carbon & 471 & 545 & 596 & 25.1 & $<0.01$ & $<0.01$ \\
\hline$>16$-Carbon & 642 & 651 & 620 & 34.9 & 0.56 & 0.03 \\
\hline \multicolumn{7}{|c|}{ Selected individual fatty acids, ${ }^{4} \mathrm{~g} / \mathrm{d}$} \\
\hline $\mathrm{C} 8: 0$ & 19.6 & 17.8 & 18.5 & 1.19 & 0.19 & 0.85 \\
\hline $\mathrm{C} 10: 0$ & 46.7 & 44.1 & 44.8 & 3.03 & 0.49 & 0.98 \\
\hline $\mathrm{C} 12: 0$ & 53.4 & 45.0 & 49.1 & 3.36 & 0.15 & 0.16 \\
\hline C14:0 & 165 & 159 & 161 & 8.9 & 0.44 & 0.93 \\
\hline C16:0 & 454 & 523 & 571 & 23.9 & $<0.01$ & $<0.01$ \\
\hline cis-9 C16:1 & 20.9 & 22.4 & 24.3 & 0.89 & $<0.01$ & $<0.01$ \\
\hline C18:0 & 164 & 173 & 155 & 7.9 & 0.92 & $<0.01$ \\
\hline cis-11 C18:1 & 9.0 & 9.1 & 9.1 & 0.42 & 0.54 & 0.73 \\
\hline cis-9,cis-12 C18:2 & 39.0 & 39.1 & 37.1 & 1.55 & 0.19 & 0.01 \\
\hline cis-9,trans-11 C18:2 & 6.4 & 6.3 & 5.8 & 0.29 & 0.21 & 0.07 \\
\hline cis-9,cis-12,cis-15 C18:3 & 5.4 & 5.1 & 4.9 & 0.23 & $<0.01$ & 0.14 \\
\hline
\end{tabular}

${ }^{1} \mathrm{CON}=$ control diet, no addition of palmitic acid; PA-TG = palmitic acid fed as triglyceride supplement; PA-FA = palmitic acid fed as free fatty acid supplement.

${ }^{2} P$-values associated with contrasts: (1) the effect of PA treatments [CON vs. PA; $\left.1 / 2(\mathrm{PA}-\mathrm{TG}+\mathrm{PA}-\mathrm{FA})\right]$, and (2) the effect of palmitic acid fed as triglycerides or free fatty acids (PA-TG vs. PA-FA).

${ }^{3}$ De novo fatty acids originate from mammary de novo synthesis $(<16$ carbons), preformed fatty acids originate from extraction from plasma ( $>16$ carbons), and 16-carbon fatty acids originate from both sources (C16:0 plus cis-9 C16:1).

${ }^{4} \mathrm{~A}$ total of approximately 80 individual fatty acids were quantified. Only select fatty acids are reported in the table. 
reaching the intestine compared with previous studies that fed partially or fully hydrogenated tallow. This hypothesis deserves further investigation. Overall, our results indicate that the degree of esterification is a major factor affecting digestibility of supplemental fat, and the magnitude of the response is influenced by the FA profile of the supplement.

Overall, we observed that PA treatments did not affect milk yield, but increased 3.5\% FCM and ECM compared with CON. Although studies with C16:0 supplements have reported some contradictory results regarding milk yield, most have shown that these supplements increase 3.5\% FCM and ECM (e.g., Lock et al., 2013; de Souza et al., 2017, 2018). Additionally, PA treatments reduced milk protein content in our study, but milk protein yield was not affected. Reductions in milk protein content, absent changes in milk protein yield, were consistently observed when responses to several sources of supplemental fat were reviewed (Rabiee et al., 2012). In contrast, we observed that PA-FA tended to increase milk yield and $3.5 \%$ FCM compared with PA-TG. These results are likely due to the increased DMI and FA digestibility for the PA-FA treatment, compared with PA-TG. This would also explain the differences we observed in BW gain between PA-FA (0.50 $\mathrm{kg} / \mathrm{d})$ compared with PA-TG $(0.25 \mathrm{~kg} / \mathrm{d})$. As discussed by Boerman et al. (2015), depending on the stage of lactation and energy balance, an increase in diet energy density via dietary FA supplements could increase milk production, milk fat yield, and body reserves as long as dietary FA supplements do not reduce DMI or negatively affect the digestibility of other nutrients.

Most of our short-term studies involving C16:0 supplements (fed at 1.5 to $2.0 \%$ diet DM) to mid-lactation cows have indicated increases in milk fat yield of $\sim 100$ g/d (Lock et al., 2013; Piantoni et al., 2013; de Souza et al., 2017). Recently, de Souza and Lock (2018a) observed that feeding a C16:0 supplement (1.5\% diet DM) over a 10-wk period increased milk fat yield by $\sim 150$ $\mathrm{g} / \mathrm{d}$. In our study, PA treatments increased milk fat content $(+0.20$ percentage points) and milk fat yield $(+80 \mathrm{~g} / \mathrm{d})$ compared with $\mathrm{CON}$, but the increase in milk fat yield tended to be greater for PA-FA than for PA-TG. When we calculated the FAYR based on FA intake, the results indicated a greater FA transfer for PA-FA than for PA-TG (18.4 and $23.8 \%$ for PA-TG and PA-FA, respectively). However, when we calculated FAYR based on absorbed FA, transfer efficiency was similar for both supplements (36.0 and $36.1 \%$ for PA-TG and PA-FA, respectively). Using duodenal infusions of C16:0, Enjalbert et al. (2000) reported an apparent FAYR of $46.7 \%$ for C16:0, whereas the transfer efficiency from diet to milk fat ranged from 16 to $24 \%$ in studies feeding C16:0-enriched supplements (Lock et al., 2013; Piantoni et al., 2013). Therefore, differences in milk fat responses between PA-FA and PA-TG are likely explained by differences in FA digestibility rather than the extraction and incorporation of these FA into milk fat.

The increase in milk fat associated with our PA treatments occurred due to an increase in the yield of 16-carbon milk FA. This finding agrees with several previous studies that fed C16:0 supplements (Lock et al., 2013; Piantoni et al., 2013). Tzompa-Sosa et al. (2014) suggested that an increase in the availability of C16:0 for lipid synthesis in mammary epithelial cells may increase the activity of glycerol-3-phosphate acyltransferase in the mammary gland, therefore increasing the proportion of C16:0 acylated at sn- 1 at the expense of sn-2. Other FA would counterbalance the decrease in the amount of $\mathrm{C} 16: 0$ at sn-2. This could explain why our PA treatments increased the yield of mixed-source FA without reducing the yield of de novo and preformed FA not only by increasing TG synthesis, but also by changing the FA interpositional distribution in the TG. Additionally, we observed that PA-TG increased the yield of preformed FA, compared with PA-FA, and this was mainly the result of increased cis-9 C18:1. Increased milk cis-9 C18:1 associated with C16:0 supplementation likely occurs to maintain milk fluidity (Jensen, 2002).

\section{CONCLUSIONS}

In conclusion, feeding C16:0 supplements increased NDF digestibility, milk fat yield, 3.5\% FCM, ECM, and feed efficiency of mid-lactation dairy cows. Also, the production responses of dairy cows to C16:0 tended to be greater for a FA compared with a TG supplement, which occurred due to the lower FA digestibility of PATG compared with PA-FA.

\section{ACKNOWLEDGMENTS}

We thank the Michigan Alliance for Animal Agriculture (East Lansing, MI) and Al Ames (NutriLinx LLC, Hardwick, VT) for financial support of this study. We acknowledge C. Preseault, Y. Sun, J. L. Garver, S. E. Schmidt, M. Western, K. Wu, K. Spaans, J. L. Spaans, and T. N. Bryant (all in the Department of Animal Science, Michigan State University), and the staff of the Michigan State University Dairy Cattle Teaching and Research Center for their assistance in this experiment. Jonas de Souza was supported by a $\mathrm{PhD}$ fellowship from Coordenação de Aperfoiçamento de Pessoal de Nivel Superior (CAPES) from the Brazilian Ministry of Education (Brasilia, DF, Brazil). 


\section{REFERENCES}

Allen, M. S. 2000. Effects of diet on short-term regulation of feed intake by lactating dairy cows. J. Dairy Sci. 83:1598-1624.

AOAC. 1990. Official Methods of Analysis. 15th ed. AOAC, Arlington, VA.

AOCS. 2013. Official methods and recommended practices of the AOCS (6th ed.). Vol 3. Am. Oil Chem. Soc., Urbana, IL.

Boerman, J. P., J. de Souza, and A. L. Lock. 2017. Milk production and nutrient digestibility responses to increasing levels of stearic acid supplementation of dairy cows. J. Dairy Sci. 100:2729-2738.

Boerman, J. P., J. L. Firkins, N. R. St-Pierre, and A. L. Lock. 2015. Intestinal digestibility of long-chain fatty acids in lactating dairy cows: A meta-analysis and meta regression. J. Dairy Sci. 98:88898903.

Bremmer, D. R., L. D. Ruppert, J. H. Clark, and J. K. Drackley. 1998. Effects of chain length and unsaturation of fatty acid mixtures infused into the abomasum of lactating dairy cows. J. Dairy Sci. $81: 176-188$.

Cochran, R. C., D. C. Adams, J. D. Wallace, and M. L. Galyean. 1986. Predicting the digestibility of different diets with internal markers: Evaluation of four potential markers. J. Anim. Sci. 63:1476-1483.

de Souza, J., J. L. Garver, C. L. Preseault, and A. L. Lock. 2017. Effects of prill size of a palmitic acid-enriched fat supplement on yield of milk and milk components and nutrient digestibility of dairy cows. J. Dairy Sci. 100:379-384.

de Souza, J., and A. L. Lock. 2018a. Long-term palmitic acid supplementation interacts with parity in lactating dairy cows: production responses, nutrient digestibility, and energy partitioning. J. Dairy Sci. 101:3044-3056.

de Souza, J., and A. L. Lock. 2018b. Short communication: Comparison of a palmitic acid-enriched triglyceride supplement and calcium salts of palm fatty acids supplement on production responses of dairy cows. J. Dairy Sci. 101:3110-3117.

de Souza, J., C. L. Preseault, and A. L. Lock. 2018. Altering the ratio of dietary palmitic, stearic, and oleic acids in diets with or without whole cottonseed affects nutrient digestibility, energy partitioning, and production responses of dairy cows. J. Dairy Sci. 101:172-185.

Doreau, M., and Y. Chilliard. 1997. Digestion and metabolism of dietary fat in farm animals. Br. J. Nutr. 78(Suppl. 1):S15-S35.

Drackley, J. K. 2000. Lipid Metabolism. Pages 97-119 in Farm Animal Metabolism and Nutrition. J. P. F. D’Mello, ed. CABI Publishing, New York, NY.

Elliott, J. P., J. K. Drackley, A. D. Beaulieu, C. G. Aldrich, and N. R. Merchen. 1999. Effects of saturation and esterification of fat sources on site and extent of digestion in steers: Digestion of fatty acids, triglycerides, and energy. J. Anim. Sci. 77:1919-1929.

Elliott, J. P., T. R. Overton, and J. K. Drackley. 1994. Digestibility and effects of three forms of mostly saturated fatty acids. J. Dairy Sci. 77:789-798.

Enjalbert, F., M. C. Nicot, C. Bayourthe, and R. Moncoulon. 2000 Effects of duodenal infusions of palmitic, stearic, or oleic acids on milk composition and physical properties of butter. J. Dairy Sci. 83:1428-1433

Grummer, R. R. 1988. Influence of prilled fat and calcium salts of palm oil fatty acids on ruminant fermentation and nutrient digestibility. J. Dairy Sci. 71:117-123.

Hackmann, T. J., and J. L. Firkins. 2015. Electron transport phosphorylation in rumen butyrivibrios: Unprecedented ATP yield for glucose fermentation to butyrate. Front. Microbiol. 6:1-11. https:/ /doi.org/10.3389/fmicb.2015.00622.

Jenkins, T. C., and B. F. Jenny. 1992. Nutrient digestion and lactation performance of dairy cows fed combinations of prilled fat and canola oil. J. Dairy Sci. 75:796-803.
Jensen, R. G. 2002. Invited review: The composition of bovine milk lipids: January 1995 to December 2000. J. Dairy Sci. 85:295-350.

Johnson, T. O., G. E. Mitchell Jr., R. E. Tucker, and G. T. Schelling. 1974. Pancreatic lipase secretion by sheep. J. Anim. Sci. 39:947951.

Litherland, N. B., S. Thire, A. D. Beaulieu, C. K. Reynolds, J. A Benson, and J. K. Drackley. 2005. Dry matter intake is decreased more by abomasal infusion of unsaturated free fatty acids than by unsaturated triglycerides. J. Dairy Sci. 88:632-643.

Lock, A. L., C. L. Preseault, J. E. Rico, K. E. DeLand, and M. S. Allen. 2013. Feeding a C16:0-enriched fat supplement increased the yield of milk fat and improved conversion of feed to milk. J. Dairy Sci. 96:6650-6659.

Mosley, S. A., E. E. Mosley, B. Hatch, J. I. Szasz, A. Corato, N. Zacharias, D. Howes, and M. A. McGuire. 2007. Effect of varying levels of fatty acids from palm oil on feed intake and milk production in Holstein cows. J. Dairy Sci. 90:987-993.

NRC. 2001. Nutrient Requirements of Dairy Cattle. 7th rev. ed. National Acad. Sci., Washington D.C.

Palmquist, D. L. 1994. The role of dietary fats in efficiency of ruminants. J. Nutr. 124:1377S-1382S

Pantoja, J., J. L. Firkins, and M. L. Eastridge. 1995. Site of digestion and milk production by cows fed fats differing in saturation, esterification, and chain length. J. Dairy Sci. 78:2247-2258.

Piantoni, P., A. L. Lock, and M. S. Allen. 2013. Palmitic acid increased yields of milk and milk fat and nutrient digestibility across production level of lactating cows. J. Dairy Sci. 96:7143-7154.

Rabiee, A. R., K. Breinhild, W. Scott, H. M. Golder, E. Block, and I. J. Lean. 2012. Effect of fat additions to diets of dairy cattle on milk production and components: A meta-analysis and metaregression. J. Dairy Sci. 95:3225-3247.

Rico, D. E., Y. Ying, and K. J. Harvatine. 2014a. Effect of a highpalmitic acid fat supplement on milk production and apparent total-tract digestibility in high- and low-milk yield dairy cows. J. Dairy Sci. 97:3739-3751.

Rico, J. E., M. S. Allen, and A. L. Lock. 2014b. Compared with stearic acid, palmitic acid increased the yield of milk fat and improved feed efficiency across production level of cows. J. Dairy Sci. 97:1057-1066

Rico, J. E., J. de Souza, M. S. Allen, and A. L. Lock. 2017. Nutrient digestibility and milk production responses to increasing levels of palmitic acid supplementation vary in cows receiving diets with or without whole cottonseed. J. Anim. Sci. 95:436-446.

Simas, J. M., J. T. Huber, C. B. Theurer, K. H. Chen, F. A. P. Santos, and Z. Wu. 1998. Influence of sorghum grain processing on performance and nutrient digestibilities in dairy cows fed varying concentrations of fat. J. Dairy Sci. 81:1966-1971.

Tzompa-Sosa, D. A., G. A. van Aken, A. C. M. van Hooijdonk, and H. J. F. van Valenberg. 2014. Influence of C16:0 and long-chain saturated fatty acids on normal variation of bovine milk fat triacylglycerol structure. J. Dairy Sci. 97:4542-4551.

Van Soest, P. J., J. B. Roberson, and B. A. Lewis. 1991. Methods for dietary fiber, neutral detergent fiber, and nonstarch polysaccharides in relation to animal nutrition. J. Dairy Sci. 74:3583-3597.

Weiss, W. P., J. M. Pinos-Rodríguez, and D. J. Wyatt. 2011. The value of different fat supplements as sources of digestible energy for lactating dairy cows. J. Dairy Sci. 94:931-939.

Weiss, W. P., and D. J. Wyatt. 2004. Digestible energy values of diets with different fat supplements when fed to lactating dairy cows. J. Dairy Sci. 87:1446-1454.

Wildman, E. E., G. M. Jones, P. E. Wagner, and R. L. Bowman. 1982 A dairy cow body condition scoring system and its relationship to selected production characteristics. J. Dairy Sci. 65:495-501. 